\title{
Deformation and Failure Characteristics and Control Technology of Roadway Surrounding Rock in Deep Coal Mines
}

\author{
Jucai Chang, Dong Li $\mathbb{D}$, Tengfei Xie, Wenbao Shi, and Kai He $\mathbb{D}$ \\ Key Laboratory of Safe and Effective Coal Mining of the Ministry of Education, Anhui University of Science and Technology, \\ Huainan 232001, China \\ Correspondence should be addressed to Dong Li; austerlidong@163.com
}

Received 28 June 2020; Revised 20 August 2020; Accepted 10 September 2020; Published 22 September 2020

Academic Editor: Hualei Zhang

Copyright (C) 2020 Jucai Chang et al. This is an open access article distributed under the Creative Commons Attribution License, which permits unrestricted use, distribution, and reproduction in any medium, provided the original work is properly cited.

\begin{abstract}
With the increase in mining depth, the problem of the floor heave of a roadway is becoming increasingly prominent. Solving this problem for a deep high-stress roadway is the key to ensure safe supply and utilization of coal resources in China. This study investigates the floor heave of a horizontal transportation rock roadway at the depth of $960 \mathrm{~m}$ at the Xieyi Mine. A four-way loading simulation test frame similar to the Xieyi Mine was used to reproduce the high-stress environment of a deep roadway by loading different pressures on the roof, floor, and two sides of the roadway. The experimental results show that after the tunnel had been excavated, the surrounding rock failure could be divided into three stages: the initial deformation stage, fissure development stage, and mild deformation stage. The destruction time periods of these stages were $0-0.5 \mathrm{~h}, 0.5-2 \mathrm{~h}$, and $2-6 \mathrm{~h}$, and the destruction ranges were $0.4 \mathrm{~m}, 1 \mathrm{~m}$, and $1.5 \mathrm{~m}$, respectively. The amount of roof subsidence, the displacement of the two sides, and the floor heave influence each other, and the range of the bearing ring $(5.6 \mathrm{~m})$ of the floor is larger than that of the roof $(3.4 \mathrm{~m})$ after the surrounding rock has been damaged. The findings suggest that the floor should be supported first, before the two sides and the roof; then, the support of the key parts (roof and floor corners) should be strengthened. The roof, floor, and two sides are considered for controlling the deformation of the surrounding rock in a coupled trinity support mode. Because of the unfavorable conditions in the area, overexcavation backfill technology was used. The new support was successfully applied during the subsequent construction of the rock tunnel. Based on the long-term monitoring results of the surrounding rock deformation, the floor heave control yielded satisfactory results and maintained the long-term stability of the roadway. Therefore, this study can serve as a reference for preventing floor heave in similar high-stress roadways in the future.
\end{abstract}

\section{Introduction}

Socioeconomic development is inseparable from the exploitation and utilization of energy. In recent years, shallow coal mine resources in many mining areas have gradually been exhausted, while deep mine resources are extremely rich. Countries have entered the deep mining range, including the United States and South Africa [1-4]. At present, the buried depth of the coal seam extraction in China increases at a rate of approximately $20 \mathrm{~m}$ per year. Additionally, many coal mines are at a depth of more than $1,000 \mathrm{~m}$, exceeding the initial conceptual depth. The increase in mining depth is accompanied by many problems, such as the complex conditions of three "high" and one "disturbance." Among them, high in situ stress can easily cause issues such as rock bursts, high temperature, floor heave, a large deformation of the two sides, and roof collapse. However, the large deformation of the floor and sides causes difficulties for underground transportation and an increase in ventilation resistance, which requires a substantial amount labor and material resources for the repairs. Some deep roadways, especially soft rock roadways, need to be excavated every one or two months.

Compared with shallow roads, deep roadway floor heave is more common and severe, which has become an urgent problem for deep mining. This effect not only causes great difficulty in controlling the rock surrounding the roadway but also seriously threatens the safety of the coal mine. Since the concept of deep mining was proposed at the beginning of the 21st century, many scholars have used theoretical analysis, physical simulation experiments, and numerical 
simulations to study the deep floor heave and have proposed various solutions. Existing technologies for roadway support are relatively mature; these include primary support, secondary support, and combined support. However, there is no unified support method for a soft rock roadway with high stress. Li et al. proposed the double-yield shell coupling support technology for high-stress soft rock roadways [5]. Kang et al. improved the bolt system to prevent the deformation of surrounding rock effectively [6]. Chang et al. used hydraulic expansion bolts to control the plastic zone of the floor [7]. Gong et al. combined previous research results to manage floor heave through backfill pressure adjustments, deep grouting reinforcement, shallow hole stress relief grooves, surface pouring, and other comprehensive control schemes [8]. Sun and Wang extended the gap in the cutting corner of the roadway to transfer the maximum stress from the floor and two sides to the deep rock to relieve the pressure [9]. Sungsoon et al. used floor bolts and polyurethane resin to restrict deformation $[10,11]$. Zheng et al. controlled the floor heave using a concrete inverted arch and bolts [12]. Lai et al. used C20 concrete for the floor of a roadway and increased the bolt spacing between the roof and the two sides [13]. Liu and Ren used a C30 concrete inverted arch and corner anchor to control the floor heave [14].

Because the stress concentration at the roadway corners can easily cause failure, some scholars installed supports to these critical positions. Chen et al. controlled the floor heave by strengthening the sides of the coal pillar and corners of the roadway [15]. Wang et al. proposed the combined support scheme of "bolt at the corner of roadway floor + spraycasting concrete + U36 round shed" to improve the corner stiffness and the strength of the rock mass [16]. Cao et al. analyzed the behavior and causes of failure and proposed the use of set steel beams to optimize the bolts at the arch foot to contain the floor heave $[17,18]$. Sun et al. performed a physical simulation and determined that the displacement of the floor can cause asymmetric deformation of the roadway; then, they used an asymmetric coupling support to reduce the floor heave, based on a FLAC3D simulation $[19,20]$. According to physical simulation results, Guo et al. found that reinforcing the roof and two sides reduced the displacement of the floor [21]. Wang et al. used the combined support of bolts in the roadway floor and inverted bolts and adopted appropriate water control measures to restrict the floor heave $[22,23]$. Kulatilake et al. used 3DEC software to simulate high-stress roadways and proposed the use of $3 \mathrm{~m}$ bolts and inverted arch roadways to control the surrounding rock [24]. Mu et al. uses UDEC and other methods to study the released kinetic energy and its vibration curve and provide early warning for floor cracking [25].

The aforementioned studies used support improvements for a single component of the roadway. The surrounding rock is composed of a roof, floor, and two sides. There are significant differences in the stress state and deformation failure characteristics of each part; therefore, the entire system should be considered. In this study, the roadway that is analyzed is a transportation roadway, and a coupled support is necessary because it is not possible to support a single factor. The roof, floor, and two sides of the roadway are regarded as a whole for the support techniques. In some studies, the floor was not considered; therefore, it could not be effectively restored on site. The four-way loading plane model experimental frame can achieve fully enclosed loading on the roof, two sides, and floor of the roadway and attain high-stress environments in the deep wells by setting the loading pressures separately. Based on a similar simulation experiment of the model frame, the stress distribution, deformation, and failure characteristics of the surrounding rock of the original support scheme of a transportation roadway were replicated. The mechanism and causes of the roadway deformation were then summarized. Finally, a new floor heave treatment was proposed and applied on site for verification.

\section{Project Overview}

The Xieyi Mine is located in Huainan City, China. Its primary horizontal transportation roadway is at a depth of $-960 \mathrm{~m}$, with a length of $2400 \mathrm{~m}$. The roadway is approximately $20 \mathrm{~m}$ above the $\mathrm{C} 15$ coal seam. The coal seam is predominately embedded in mudstone, sandy mudstone, and fine sandstone. The cross-sectional shape is a semicircular arch with a straight wall, a clear width of $5.4 \mathrm{~m}$, and a clear height of $4.1 \mathrm{~m}$. The maximum horizontal principal stress in the area is $20 \mathrm{MPa}$, and the lateral pressure coefficient is approximately 1.1 . The location of the rock layer and the lithology of the roof and floor of the roadway are shown in Figure 1(a). As shown in the geological histogram, the immediate roof and floor of the roadway are sandy mudstone, and the two sides are mudstone. The lithology around the roadway is poor, and it is extremely prone to deformation and destruction from high stress and water.

The original support scheme of the roadway involved bolting, cables, and shotcreting with wire mesh on the roof and both sides; the floor was not supported. After 60 days of excavation, the maximum displacement at $1 \mathrm{~m}$ and $5 \mathrm{~m}$ of the inner side of the support were $20 \mathrm{~mm}$ and $2 \mathrm{~mm}$, respectively. The maximum displacement $1 \mathrm{~m}$ above the roof of the roadway was approximately $24 \mathrm{~mm}$, and the maximum displacement at 4-6 $\mathrm{m}$ was approximately 6-7 mm. After 100 days, the maximum displacement of the floor $1 \mathrm{~m}$ from the roadway was $55 \mathrm{~mm}$. The surrounding rock was substantially deformed; both the bolts and the cable were broken, and the floor heave was severe. As shown in Figure 1(b), the floor of the tunnel was broken, and the track moves left. Even after repeated floor-cutting work on site, the conditions were not adequate. Therefore, it was necessary to study the deformation and failure characteristics of the roadway in the laboratory and summarize the mechanism of the tunnel's deformation and failure to establish targeted floor heave control measures.

\section{Physical Modeling Experiment}

A similar simulation experiment loading system primarily includes a model steel frame, restraint channel steel, observation window, hydraulic oil circuit, and load control system. The system applies a load to the model material through cylinders and loading plates in four directions of up, down, 


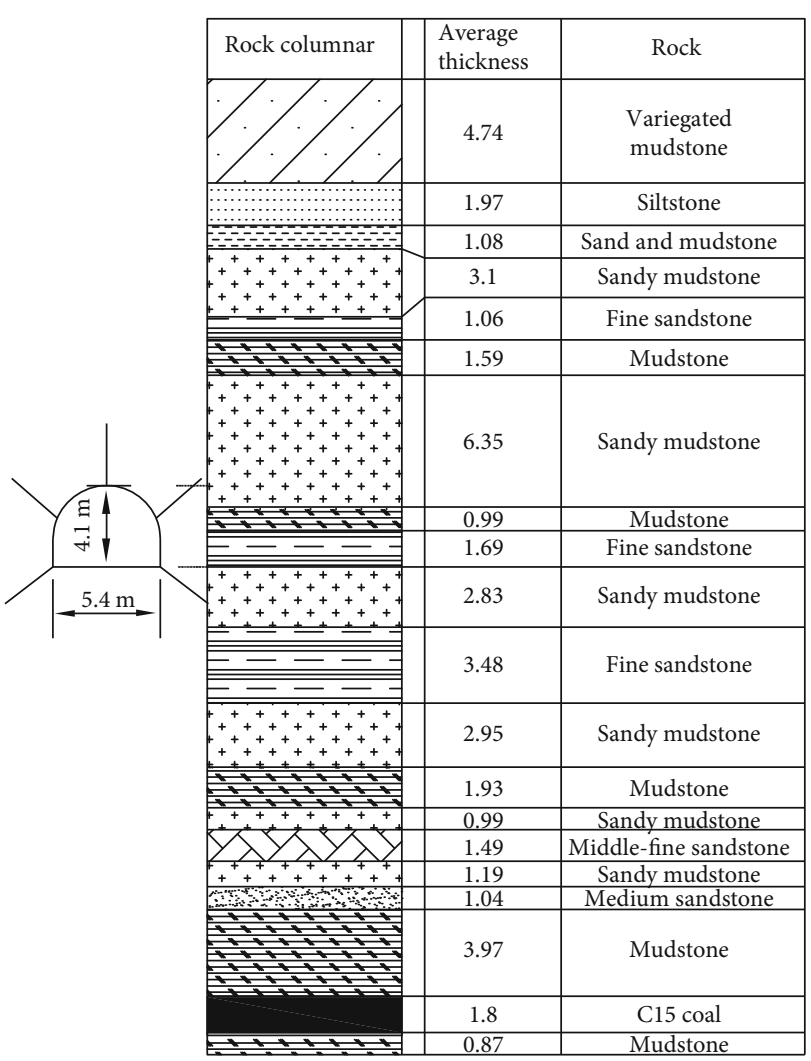

(a)

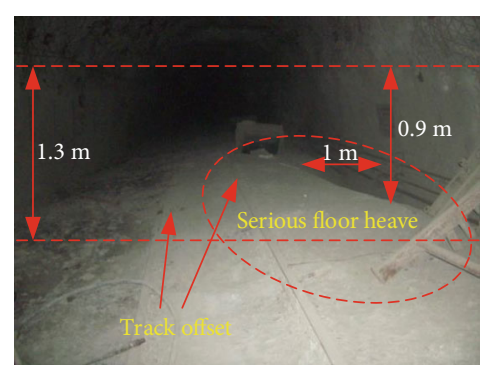

(b)

Figure 1: Roadway overview. (a) Borehole columnar section. (b) Floor heave figure.
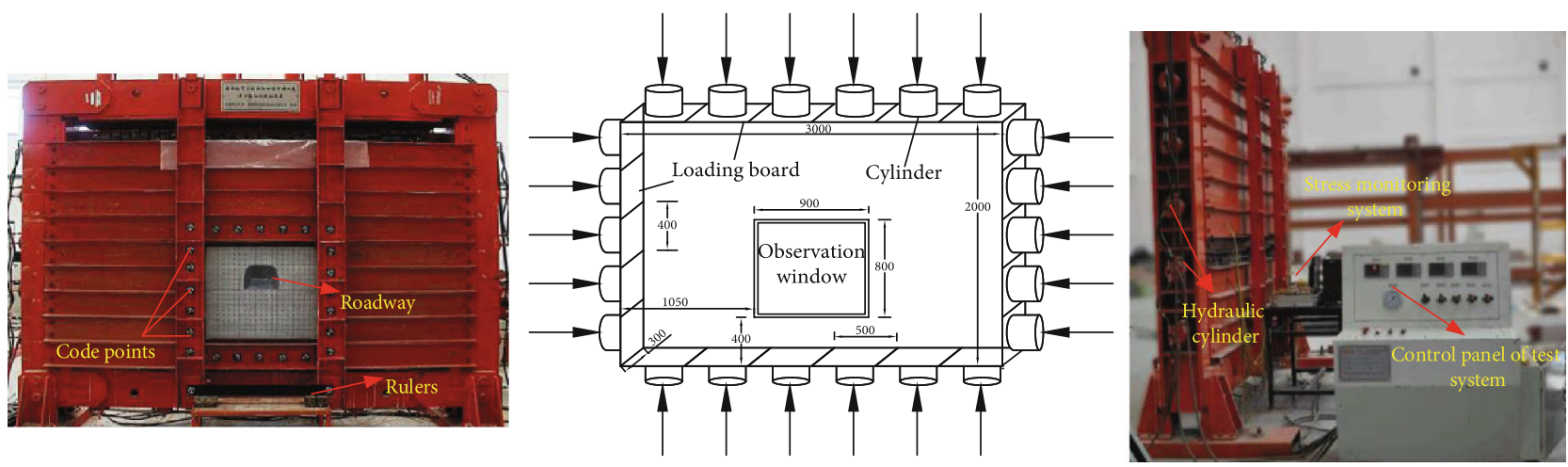

Figure 2: Model system. (a) The test model frame. (b) The model loading schematic. (c) The experiment control system and stress monitoring system.

left, and right. The dimensions of the test loading system are shown in Figure 2.

The console panel has 5 pressure control knobs and 4 display screens to display the cylinder pressure in the four directions in real time. There are 6 loading plates on the top and bottom, and 5 loading plates on the left and right, each of which corresponds to a hydraulic cylinder (Figure 2(b)). The pressure applied to the roof, sides, and floor in four directions can be controlled by a knob, and the loading board is linked in real time. The horizontal and vertical stresses in the field are transformed into corresponding cylinder pressure data, and the corresponding values are input through the control knob to realize on-site restoration of deep high-ground stress.

3.1. Similar Parameters and Material. The size of the model was $3000 \mathrm{~mm}$ (length) $\times 300 \mathrm{~mm}$ (width) $\times 2000 \mathrm{~mm}$ (height), and the cross-sectional dimension of the model of the roadway was $270 \mathrm{~mm}$ (width) $\times 205 \mathrm{~mm}$ (height). The prototype range was $60 \mathrm{~m}$ (length) $\times 6 \mathrm{~m}$ (width $) \times 40 \mathrm{~m}$ (height). 
TABLE 1: Test model similar material ratio table.

\begin{tabular}{|c|c|c|c|c|c|c|c|}
\hline \multirow{2}{*}{$\begin{array}{l}\text { Layer } \\
\text { Number }\end{array}$} & \multirow{2}{*}{ Rock } & \multirow{2}{*}{ Thickness (mm) } & \multirow{2}{*}{ Weight $(\mathrm{kg})$} & \multicolumn{4}{|c|}{ Material usage (kg) } \\
\hline & & & & Sand & Lime & Gypsum & Water \\
\hline 1 & Sandy mudstone & 49.50 & 71.28 & 61.10 & 8.32 & 3.56 & 8.55 \\
\hline 2 & Mudstone & 96.50 & 138.96 & 121.59 & 13.90 & 5.95 & 16.67 \\
\hline 3 & Sandy mudstone & 163.00 & 234.72 & 201.18 & 27.38 & 11.74 & 28.17 \\
\hline 4 & Fine sandstone & 150.00 & 216.00 & 172.80 & 16.20 & 37.80 & 25.91 \\
\hline 5 & Sandy mudstone & 150.00 & 216.00 & 185.14 & 25.20 & 10.80 & 25.92 \\
\hline 6 & Fine sandstone & 84.50 & 121.68 & 97.34 & 9.13 & 21.29 & 14.60 \\
\hline 7 & Mudstone & 49.50 & 71.28 & 62.37 & 7.13 & 3.05 & 8.55 \\
\hline 8 & Sandy mudstone & 317.50 & 457.20 & 391.88 & 53.34 & 22.86 & 54.86 \\
\hline 9 & Mudstone & 79.50 & 114.48 & 100.17 & 11.44 & 4.90 & 13.73 \\
\hline 10 & Fine sandstone & 53.00 & 76.32 & 65.42 & 6.36 & 6.36 & 9.16 \\
\hline 11 & Sandy mudstone & 155.00 & 223.20 & 191.32 & 26.04 & 11.16 & 26.79 \\
\hline 12 & Mudstone & 54.00 & 77.76 & 68.04 & 7.78 & 3.33 & 9.33 \\
\hline
\end{tabular}

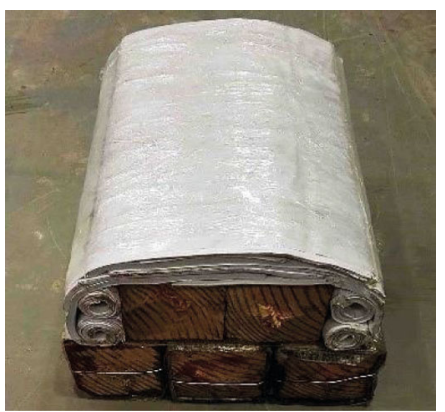

(a)

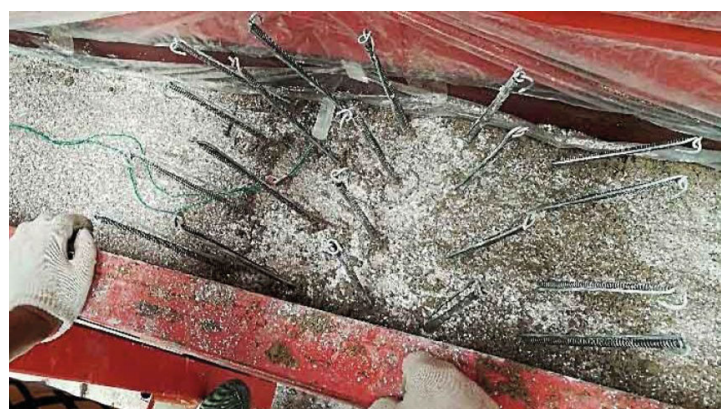

(b)

FIGURE 3: Roadway filling body and supporting structure. (a) Roadway model. (b) Roadway supporting.

According to the geological conditions and the simulation system, the geometric similarity ratio of the test is

$$
C_{l}=\frac{L_{p}}{L_{m}}=20
$$

where $L_{p}$ is prototype length and $L_{m}$ is model length.

The mechanical similar parameters are

$$
\begin{gathered}
C_{r}=C_{\rho}=\frac{\rho_{p}}{\rho_{m}}=1.7, \\
C_{\sigma}=\frac{\sigma_{p}}{\sigma_{m}}=C_{l} C_{r}=34,
\end{gathered}
$$

where $\rho_{p}$ is the average density of the prototype rock layers, with a value of $2,500 \mathrm{~kg} / \mathrm{m}^{3}$ and $\rho_{m}$ is the average density of the simulated material, with a value of $1,500 \mathrm{~kg} / \mathrm{m}^{3}$.

Ignoring the difference in the top and bottom stresses caused by self-weight and according to the above stress similarity ratio, the vertical stress in the roadway model was $0.53 \mathrm{MPa}$ and the horizontal stress was $0.59 \mathrm{MPa}$. In the model frame, the inner diameter of the jack cylinder was $0.1 \mathrm{~m}$, and its cross-sectional area was approximately
$0.00785 \mathrm{~m}^{2}$. The areas of the loaded steel plates in the vertical and horizontal directions were $0.15 \mathrm{~m}^{2}$ and $0.12 \mathrm{~m}^{2}$, respectively. The ratios of the vertical and horizontal load plates to the cylinder's cross-sectional area were 19.11 and 15.29 , respectively. Therefore, the target pressure values in the vertical and horizontal directions of the console operation were $10 \mathrm{MPa}$ and $9 \mathrm{MPa}$, respectively.

In accordance with the results of previous studies, fine sand, gypsum powder, lime powder, and water were selected as the similar materials, and the proportions of these materials were confirmed through a matching experiment. The content of each material is shown in Table 1.

3.2. Model and Monitoring. The roadway was prefabricated. Wood strips were used for filling before excavation and were extracted during excavation. The roadway was supported by a combination of steel wire mesh, bolts, and cables. The bolts and cables were made of type 15 and 16 wires, respectively. Considering the strong adhesion between the grouting bolt and surrounding rock, the cylindrical spiral spring was fixed outside the wire. The cable primarily served for suspension purpose; hence, the ends of the cables were shaped as hooks (Figure 3).

The thickness of each layer of the model was no more than $2 \mathrm{~cm}$, with mica pieces placed between the layers. The 


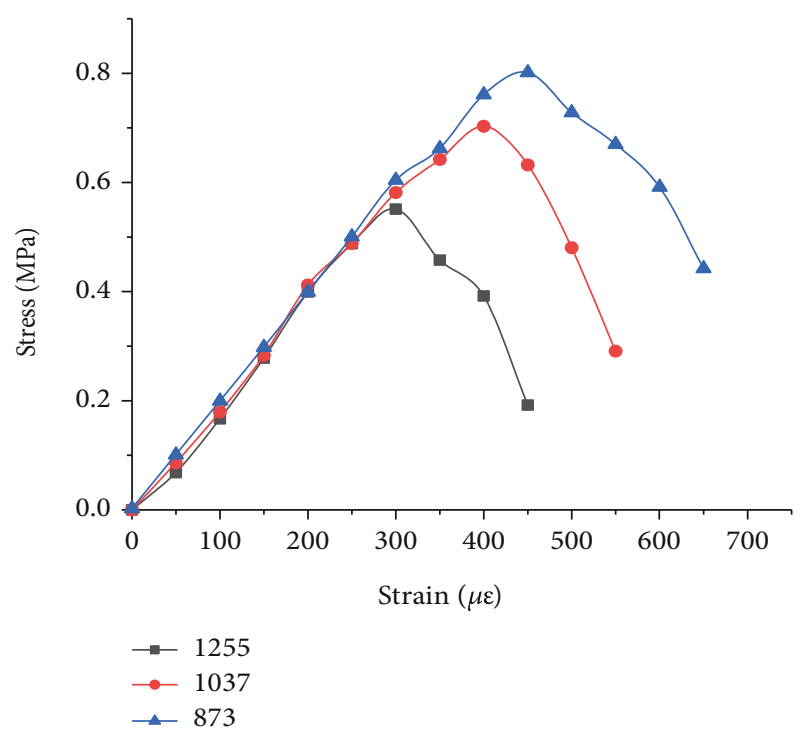

Figure 4: Strain gauge calibration curve.

joint fissures were prefabricated. Eight survey lines were arranged in the model in a pattern similar to that of the Union Jack. They were spread around the roadway, distributed to the left and right of a symmetrical axis of the roadway section. The measuring points of the roof and floor were arranged vertically in a symmetrical manner. The angle between the adjacent measuring lines formed by the line of measuring points was $45^{\circ}$.

A week after the model was created, the channel steel was removed for drying for 20 days. After the model was dry, it was placed in the loading system to apply the pressure. In order to avoid sharp damage caused by an instantaneous high load and maintain the stability of the model, an extremely low load was first applied in the vertical direction, then the left and right direction, so the loading system was in full, even contact with the test model body.

After 24 hours of stabilization, the loading was applied concurrently using the same method. Because the front observation window of the test model frame was made of an organic glass plate, the front of the model frame was heavily bulged and deformed due to the expansion and extrusion of the glass plate under the model force. For safety reasons, the load would stop increasing and stabilize after reaching the specified value. Meanwhile, stress acquisition and quasistatic displacement measurement photography were performed.

The stress data acquisition frequency was set at $10 \mathrm{~min}$. The images were captured once every hour when there is no obvious appearance change in the model, and the shooting frequency increased when the model was noticeably altered.

In addition to the aforementioned calculation, sensors were fabricated for stress monitoring and were calibrated to analyze the stress state variation due to relative strain. The laboratory calibration curve of the strain gauge used in this test is shown in Figure 4.

The three elastic stages of the curves reflect the relationship between the relative strain measured by the strain gauge

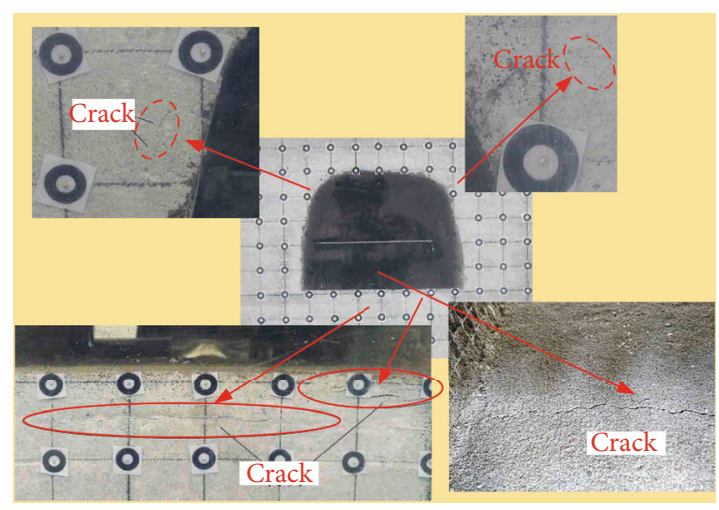

FIGURE 5: Cracks in the surrounding rock of the roadway.

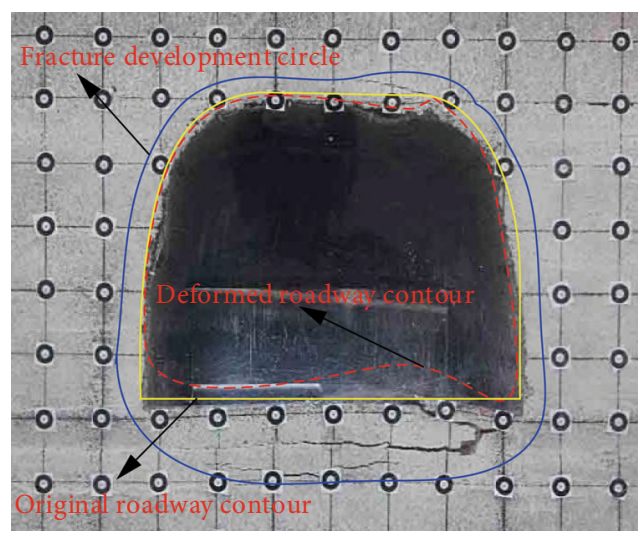

FIgURE 6: Roadway outline during slow deformation.

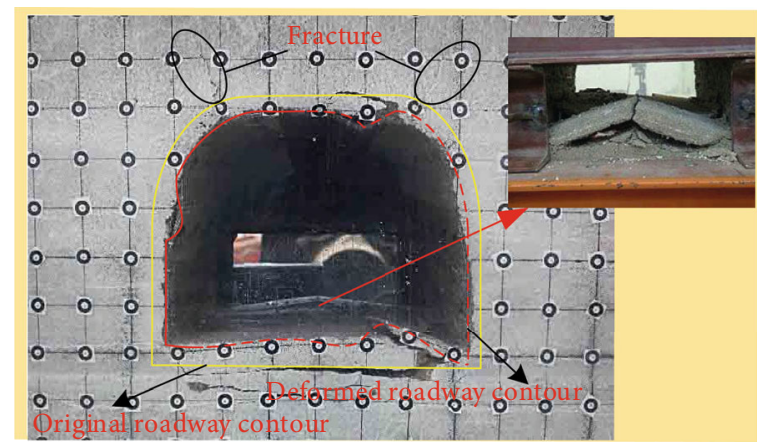

FIGURE 7: Deformation roadway profile during fissure development.

in the model and the stress state. The equation $\sigma=0.00195 \varepsilon$ was obtained by fitting the curves.

The strain sensor was connected to a CM-2B strain gauge, and the data were analyzed simultaneously. The data were collected and exported using the CM-2B-64 measuring and analysis system. The displacement was measured using a three-dimensional optical photogrammetry system, which consists of coded and noncoded points as well as scales. The principle was to take pictures of the model at different angles and calculate the corresponding point displacement using the software. Namely, this system uses a photogrammetric camera to take multiple pictures of the measured object from different observation angles (or camera stations). 


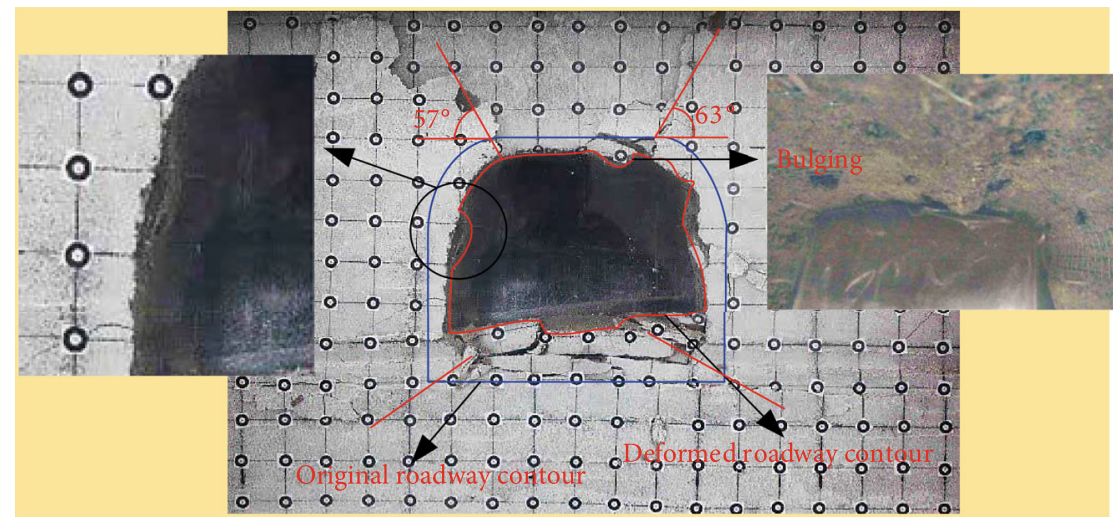

FIGURE 8: Deformation roadway profile during mitigating deformation period.

The measurement software calculates all the relevant target points and automatically calculates the three-dimensional coordinates of the mark points and the object feature points pasted in these digital pictures. The system uses a 10megapixel high-resolution digital camera, and the measurement accuracy is about $1 / 100000$ of the measured object size.

\subsection{Analysis of Experimental Results}

3.3.1. Damage Characteristics of Surrounding Rocks. Throughout the pressurization process, the deformation of the surrounding rocks could be divided into three stages: the initial deformation stage, the fissure development stage, and the mild deformation stage.

(1) Initial Deformation Stage. The following experimental data were converted into corresponding prototype data. Cracks had developed when the surrounding rock and roadway support were combined and stabilized after the roadway excavation (see Figure 5). Cracks had formed within $0.4 \mathrm{~m}$ from the surfaces of the two sides of the roadway, with a length of approximately $0.2 \mathrm{~m}$ and at the lower right corner of the roadway, with a length of $1 \mathrm{~m}$, which were caused by shear dislocation. Additionally, cracks with a length of up to $2 \mathrm{~m}$ also formed $0.4 \mathrm{~m}$ below the floor. The crack development trend was that the roadway formed a circle, conforming to the law of zonal fracture. Due to the compression and nontension of the rock stratum, with horizontal stress, the tensile strain and cracks appeared in the floor. After loading for a few minutes, the floor began to warp upwards. The roadway contour and the circular fissure development before and after deformation are shown in Figure 6.

After the roadway excavation, under the transfer of selfweight stress and horizontal stress, the floor deformed at the free surface, and the floor heave increased gradually with time. The plastic zone gradually expanded to the depth of the floor. At this time, the maximum destroying depth was approximately $1 \mathrm{~m}$. Due to self-weight stress, the surface of the roof at $2 \mathrm{~m}$ from the right side of roadway had begun to bulge.

(2) Fissure Development Stage. In the first stage, a slight damage had occurred at the floor; however, the deformation rate increased significantly after entering the second stage, resulting in severe floor heave. In the highly deformed area, the roadway floor bulged and broke (Figure 7), and the highest point of breakage was $0.5 \mathrm{~m}$ higher than the right-side corner of the roadway. The floor had broken along the axis direction of the roadway, with the most substantial floor heave in the middle of the floor. Furthermore, the deformation of the left side was significant, while that of the right side was small, and the entire roadway was noticeably compressed.

During this stage, the roof continued to sink, especially $2 \mathrm{~m}$ from the right side. The original bulging continued to develop. Approximate V-type fracture appeared at the top corner of the roadway roof, presenting obvious shear dislocation.

(3) Mild Deformation Stage. After the fissure development in the first two stages, the mild deformation stage was characterized by deformation and failure toward the end of the experiment. The rock pressure appeared as a $1.5 \mathrm{~m}$-deep fractured zone beneath the floor, from which horizontal and gravity stresses were transferred to the floor, which had a lower support strength; in addition, massive folds and block dislocations had been formed in the aforementioned zone. When the two sides converged at the center of the roadway due to the deep high-ground stress, the sectional area of the roadway was reduced by approximately $1 / 3$. Furthermore, an arc phenomenon had formed between the left side wire mesh and the spray layer and surrounding rock

Shear failure had formed at the two top corners and bottom corners of the roadway (see Figure 8). Due to the stress concentration, the entire structure appeared to have undergone X-shaped failure. According to the Mohr-Coulomb criterion, the angles of fracture were $61^{\circ}$ for the top corner $61^{\circ}, 57^{\circ}$ for the left side, and $63^{\circ}$ for the right side.

3.3.2. Displacement Analysis of Surrounding Rock. The data measured using the three-dimensional optical photogrammetry system are shown in Figure 9. The surrounding rock of the experimental roadway underwent plastic deformation within $0.5 \mathrm{~h}$ after excavation, the displacement at different locations constantly increased, and the tunnel gradually 


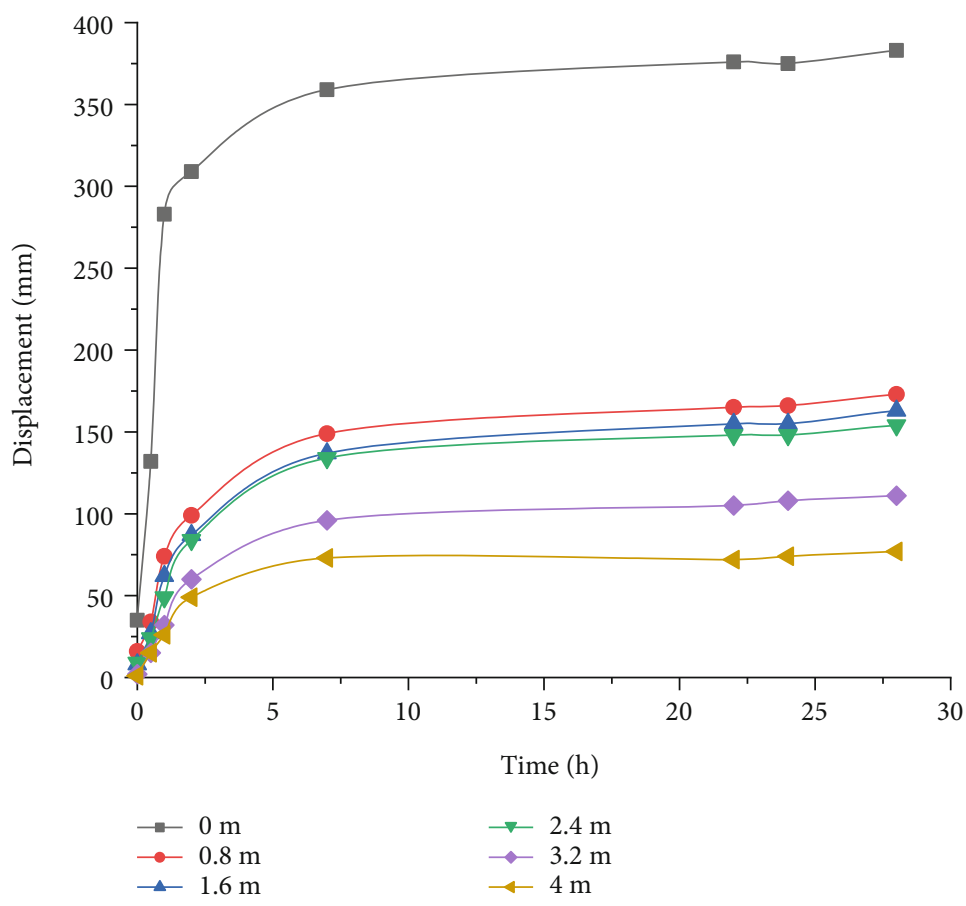

(a) Floor

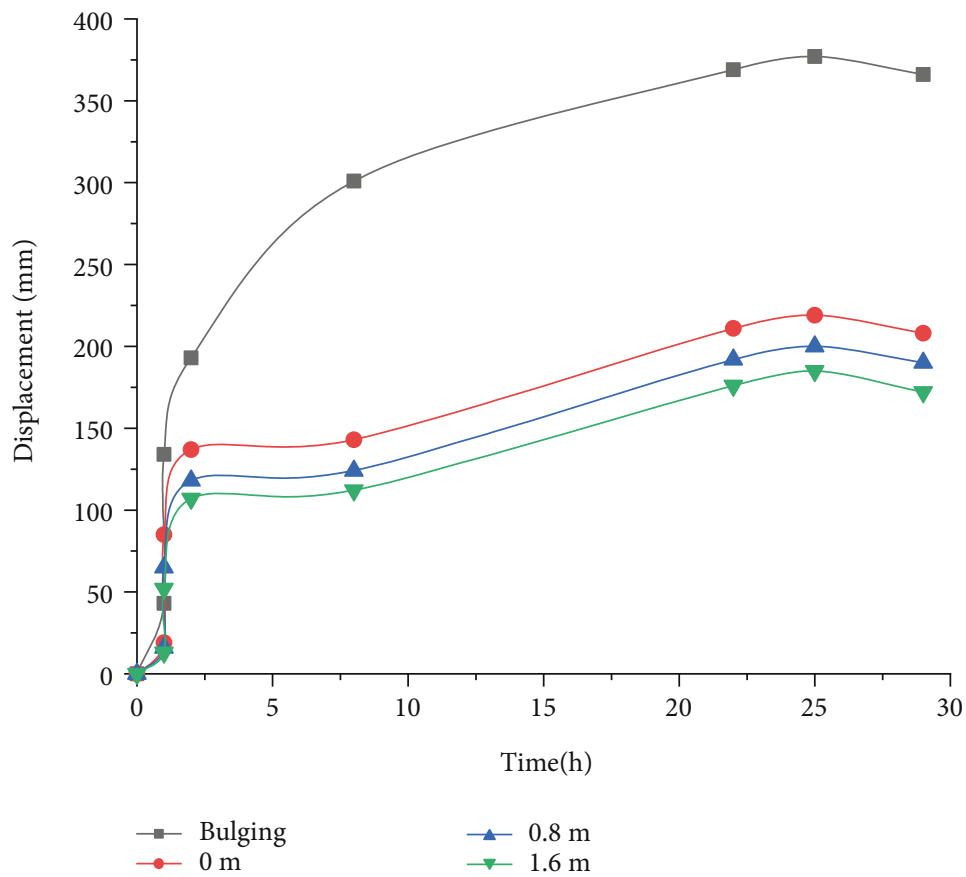

(b) Roof

Figure 9: Continued. 


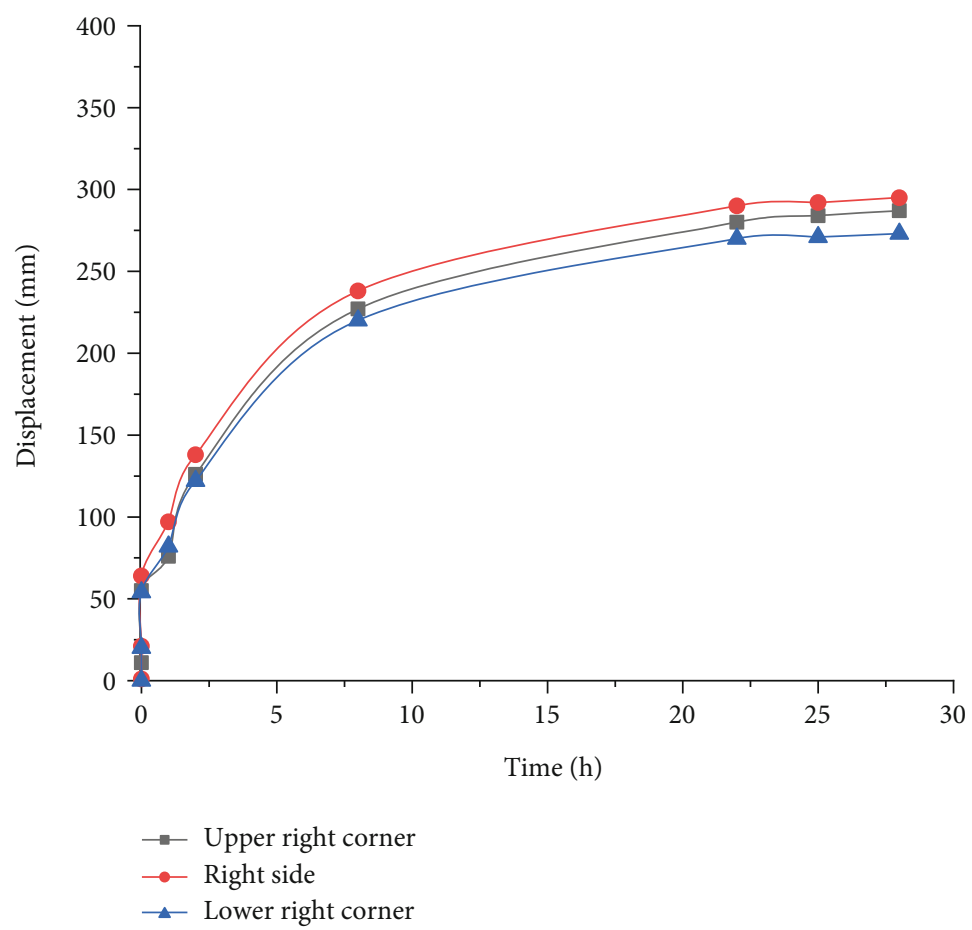

(c) Right side

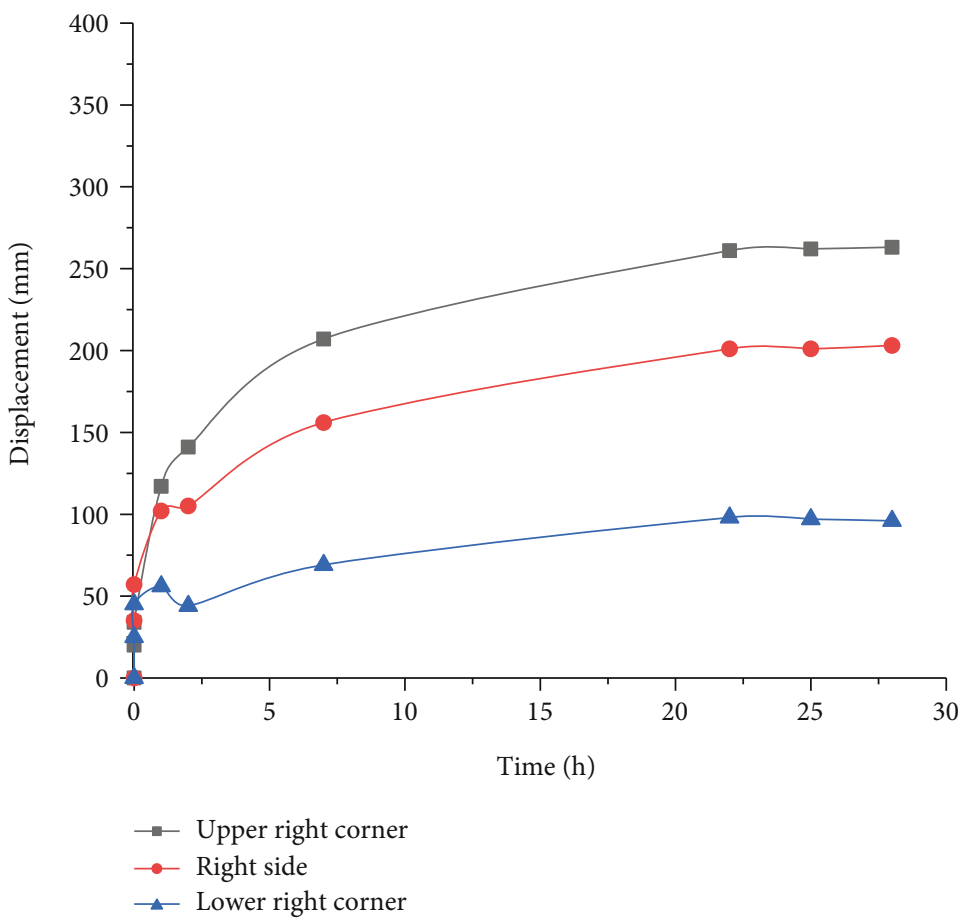

(d) Left side

FIGURE 9: Displacement of surrounding rock in roadway.

converged. Within $0.5-2 \mathrm{~h}$, both the floor and the roof underwent severe deformation, which was characterized by an increase in the displacement rate, and deep fissures continued to develop, while the time for severe deformation of the floor was $0.5-6 \mathrm{~h}$. After $6 \mathrm{~h}$, the displacement rate gradually stabilized, but the surface displacement of the floor reached $380 \mathrm{~mm}$, which could severely affect the usage of the trans- portation roadway. These three periods correspond to each of the above three stages.

Six measurement points, at depths of $0 \mathrm{~m}, 0.8 \mathrm{~m}, 1.6 \mathrm{~m}$, $2.4 \mathrm{~m}, 3.2 \mathrm{~m}$, and $4 \mathrm{~m}$ below the floor, were selected. The displacement change trend under the floor was the same as that on the floor surface, but the change rate was different. The farther away from the floor surface, the lower the change rate. 


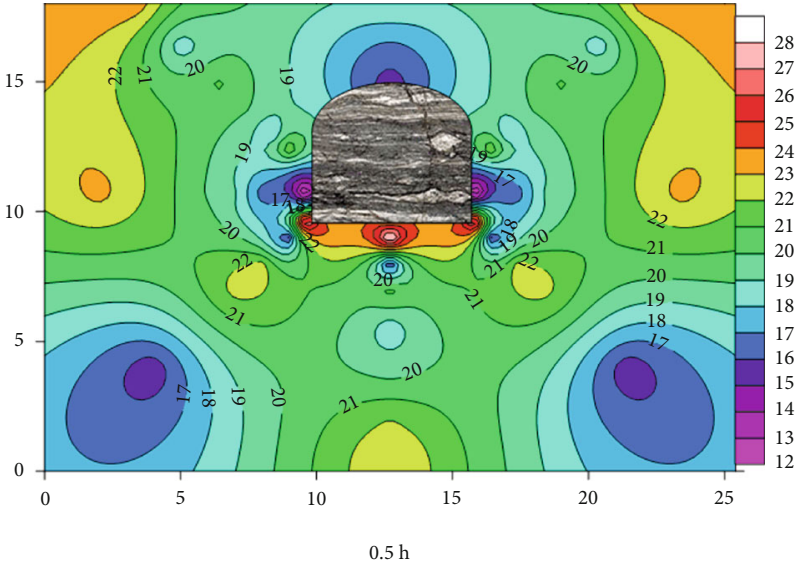

(a) $0.5 \mathrm{~h}$

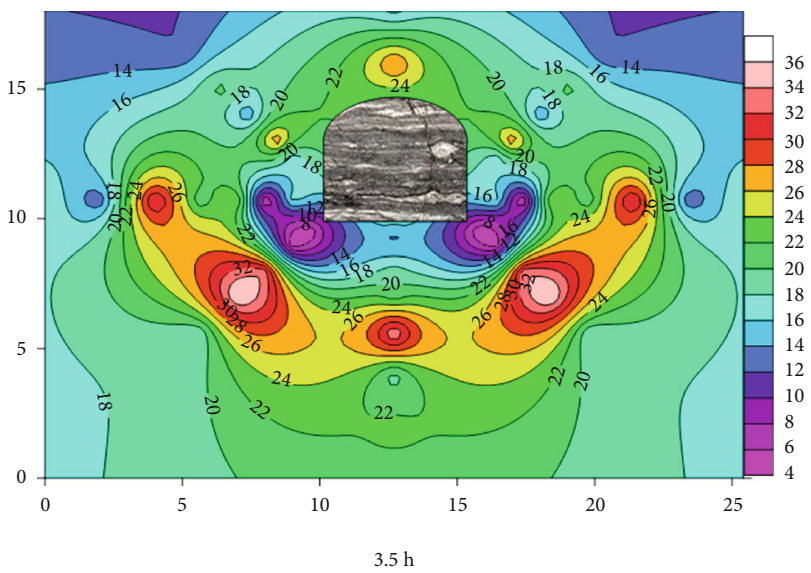

(c) $3.5 \mathrm{~h}$

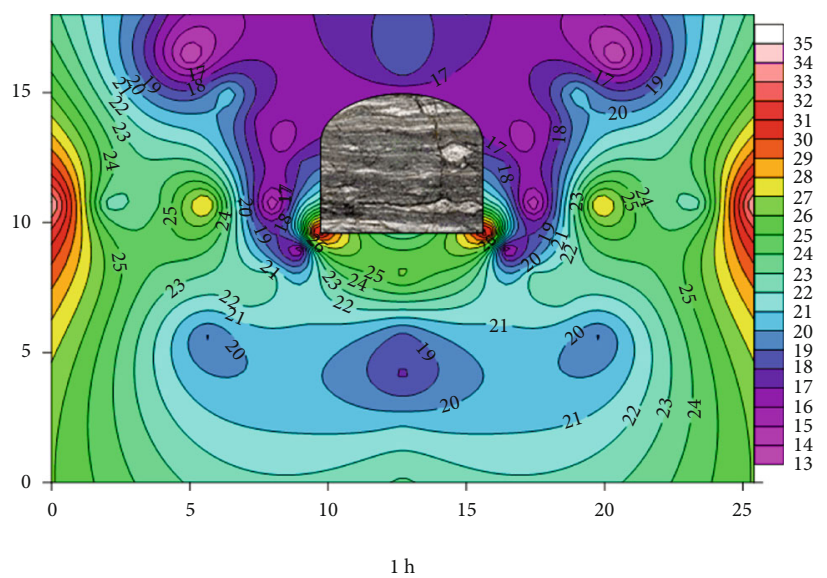

(b) $5 \mathrm{~h}$

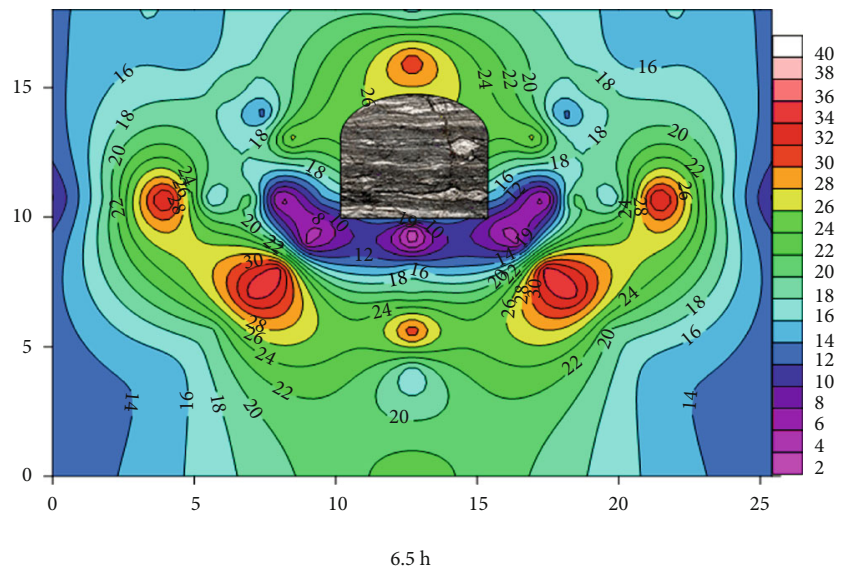

(d) $6.5 \mathrm{~h}$

FIGURE 10: Stress cloud of surrounding rock in roadway.

Additionally, four measurement points, the bulge of the roadway surface and $0 \mathrm{~m}, 0.8 \mathrm{~m}$, and $1.6 \mathrm{~m}$ above the roof were selected. The displacement trend above the roof was also the same as that on the roof surface, but with a different change rate. The farther away from the surface, the lower the rate. It can be seen from the two sides that the inward convergence of the roadway was different and represented an asymmetric deformation. During self-stabilization after the roadway excavation, deformation and destruction had occurred. Due to the strength of the support, the displacements of the roof and two sides were controlled well, the floor became a weak surface, and the stress exceeded the long-term strength of the rock. Over time, the floor was gradually destroyed at a high deformation rate.

3.3.3. Analysis on Stress Evolution of Surrounding Rocks. According to the vertical stress data measured using the strain gauge, the contour diagram was obtained using the SURFER software (Figure 10) (stress units of MPa).

After roadway excavation, in the initial deformation stage, the side wall was in the stress reduction area, and the stress increased until the cracks had become more serious during the fissure development stage. The side walls converged when squeezed under the vertical stress. However, the stress concentration was maintained at the corner of the floor, and within $8 \mathrm{~m}$, below the floor until the second stage. The stress release from the floor bulged upwards, causing damage, and the stress concentration occurred in the range of 1.5-3.0 m above the roof. In combination with the displacement changes and stress cloud, the roof stress shifted to the two sides and floor during the fissure development stage and released stress during the mild deformation stage.

During the first stage (see Figures 5 and 10(a)), the roof was in the state of pressure relief, the floor was in the free surface, and a stress concentration was formed at the center and corner of the floor, which resulted in the floor deforming and generating cracks. Because of a stress concentration near the top corner, a small crack appeared in the side, and the floor suffered more damage than the side did. With time, the roof of the roadway was still under pressure relief, and the stress concentration factor of the floor reached 1.3. Additionally, the damage to the floor had increased. However, the stress at the midpoint and floor corner of the support was greater than that of the protolith, and the degree of damage to the support became larger. During the mild deformation stage, the roof and floor were in the pressure relief state, the top corner and the roof were in the stress concentration state. The top corner and the roof began to gradually fracture. 


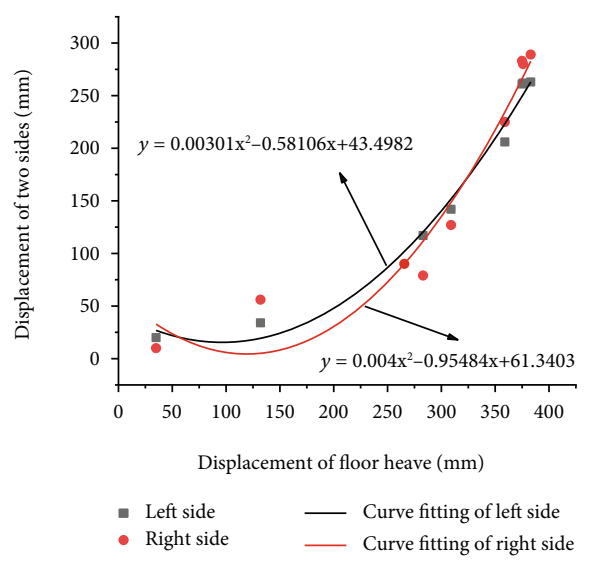

(a)

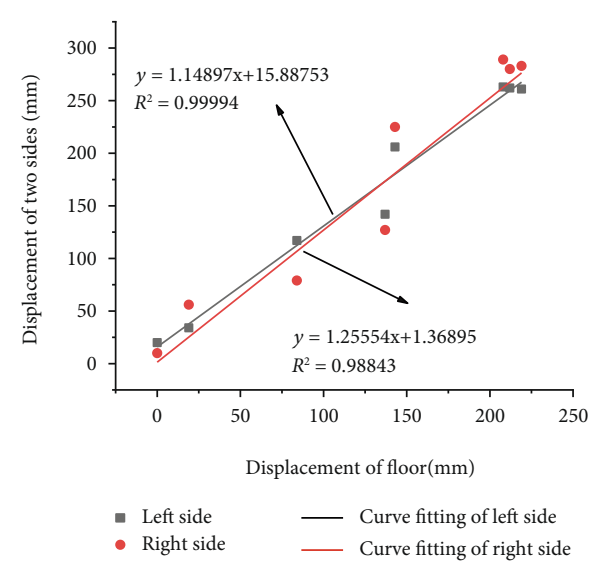

(b)

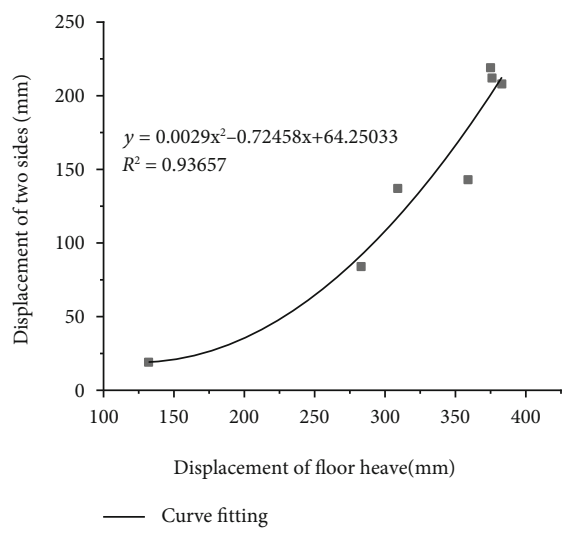

(c)

FIGURE 11: The displacement relationships between the floor heave, two sides, and roof. (a) The relationship between floor heave and the displacement of the two sides. (b) The relationship between roof subsidence and the deformation of the two sides. (c) The relationship between roof subsidence and floor heave.

3.3.4. Displacement Relation of Floor, Two Sides, and Roof. The curves of the vertical displacement of the floor and roof and the horizontal displacement of the two sides were drawn and fitted (Figure 11). The floor heave is a quadratic function with the displacement of the two sides. With the increase in the floor heave, the deformation of the two sides intensified, especially after the floor heave reached $200 \mathrm{~mm}$ when the deformation rate was more apparent. There is a linear relationship between the roof subsidence and the displacement of the two sides. The deformation of the two sides was larger than that of the roof, and the two sides underwent asymmetric deformation. The deformation of the right side was larger than that of the left side after $140 \mathrm{~mm}$. There is a quadratic relationship between the roof subsidence and the displacement of floor. After the floor heave reached $250 \mathrm{~mm}$, the deformation speed of roof subsidence increased sharply, which indicates that support gradually began to lose stability.

According to the analysis presented above, the deformation of the floor heave affected the two sides and the two sides affected the roof. The roof subsidence caused further deformation of the floor. In order to control the floor heave, it is necessary to consider the two sides and the roof. To maintain the roof, we need to control the two sides, and to control the two sides, we need to protect the floor. The roof, sides, and

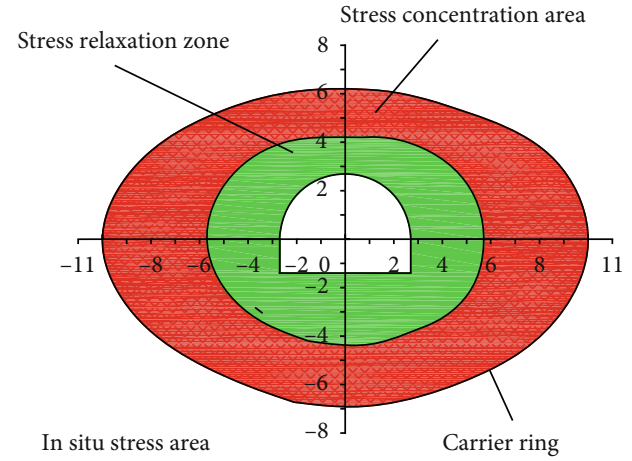

FIGURE 12: Schematic diagram of partition.

floor are interdependent and influence each other in a closed-loop relationship. Therefore, restricting surrounding rock deformation cannot be accomplished by individually controlling the two sides, floor, or the roof, but a combination of the three.

\section{Discussion}

After the excavation of a deep high-geostress roadway, the surrounding rock is broken; simultaneously, the support is 

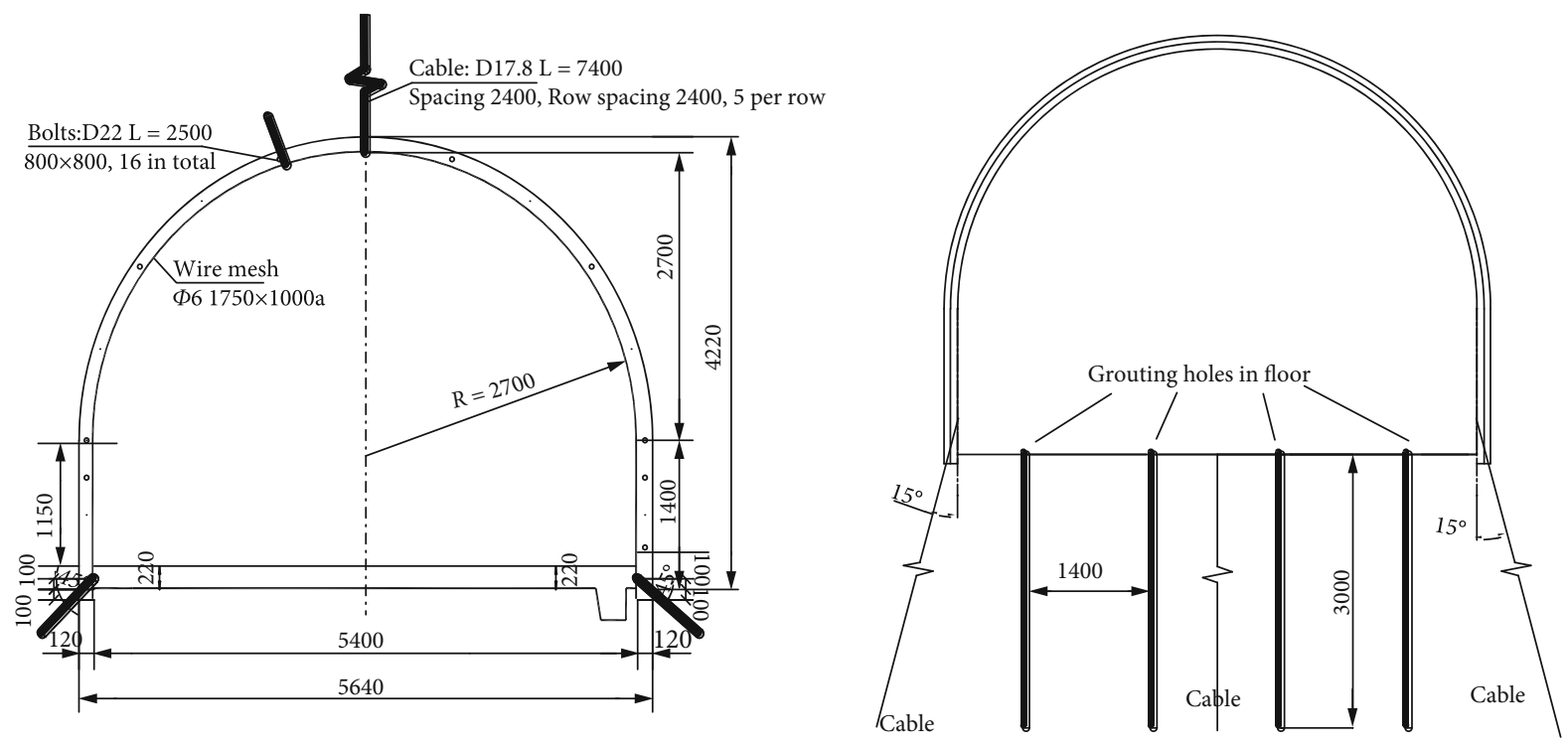

(a)
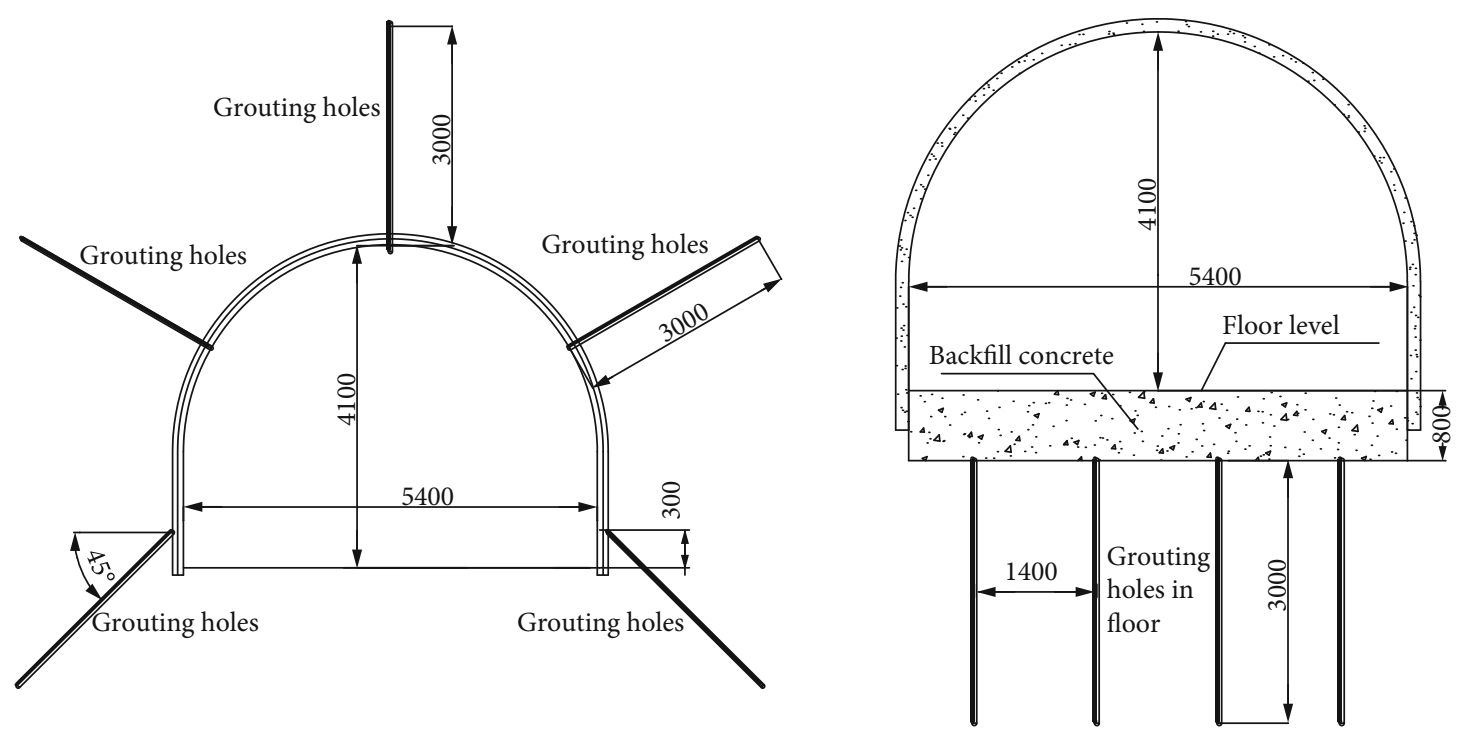

(b)

FIGURE 13: Cross-section of roadway.

provided, and thereafter, the stress is redistributed. The initial support condition is better, and the stress begins to concentrate on the roof, two sides, and the floor, especially in the key parts. With time, the stress concentration range is widened. Because the floor is not supported, it becomes a weak load-bearing surface to which the high geostress is continuously transferred. The floor first undergoes shear and tension damage. The damage range of the surrounding rock is $0.5 \mathrm{~m}$ in initial deformation stage, and the stability of the surrounding rock of the roadway is lost. Thus, the two sides and the roof converge further toward the roadway. After the destruction of the two sides, the roof sinks further. After the destruction of the roof, the entire surrounding rock structure gradually destabilizes. This further enlarges the destruction range of the floor and generates an abscission layer underneath, with approximately $1 \mathrm{~m}$ of the destruction range of the surrounding rock in the fissure development stage. Then, in key parts, such as the roof corners and floor corners of roadway, larger cracks will be generated due to shear failure, the four corners are X-shaped, and the bearing capacity of the surrounding rock will be further weakened, which will widen the damage range of roof, two sides, and floor-the failure range of the surrounding rock is about $1.5 \mathrm{~m}$ in the second stage.

After the failure of the roadway, the surrounding rock is divided into a decreasing stress area, rising stress area, and primary rock stress area (see Figure 12). The load-bearing ring is $3.4 \mathrm{~m}$ above the roadway and $5.6 \mathrm{~m}$ below the roadway, and the decreasing stress zone is $1.5 \mathrm{~m}$ above the roadway and $3 \mathrm{~m}$ below the roadway. The range of the load-bearing ring and the decreasing stress zone for the floor is larger than that of roof. 


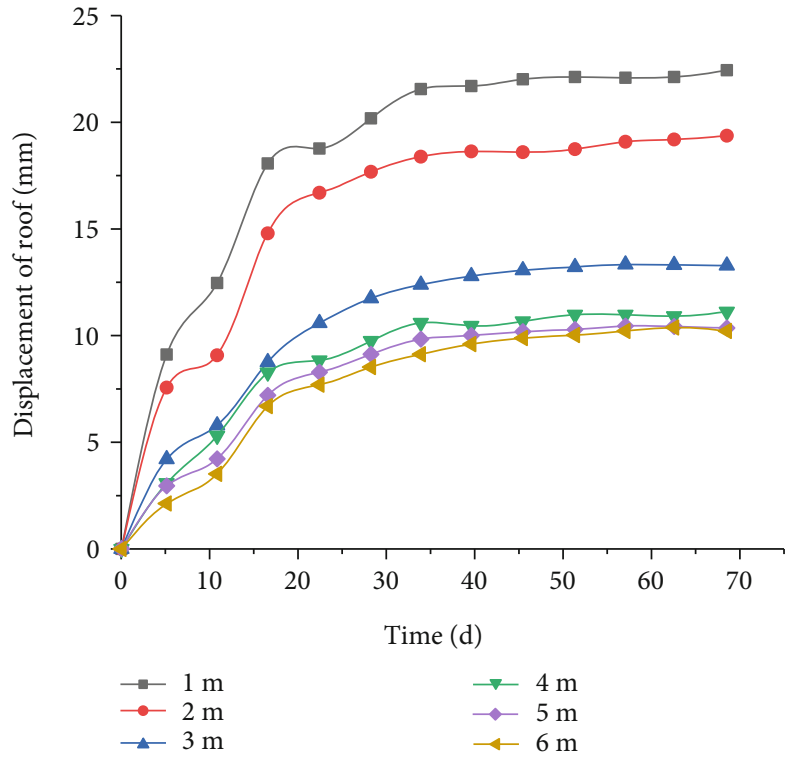

(a)

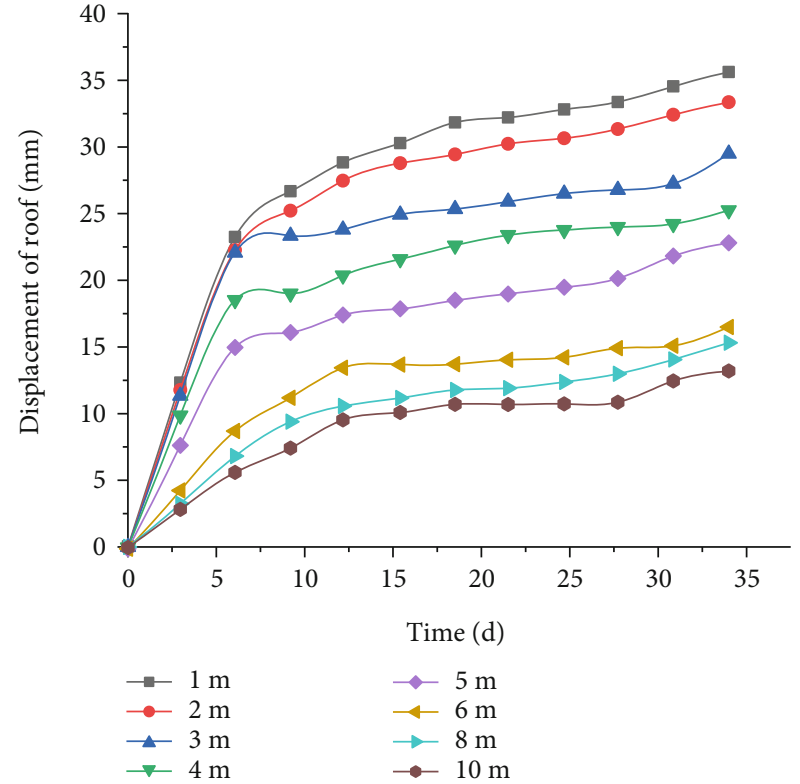

(b)

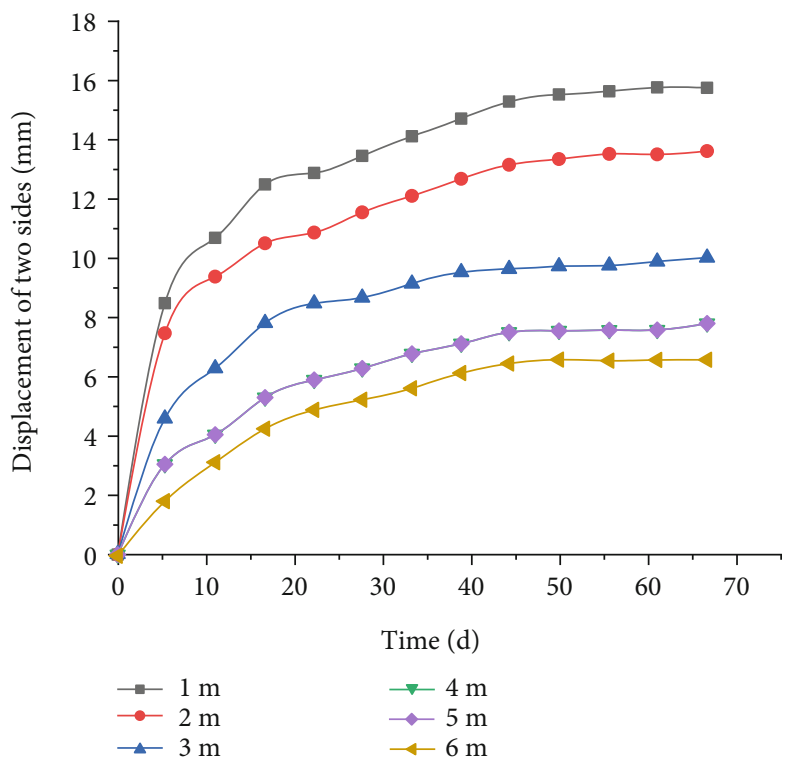

(c)

FIGURE 14: Displacement curve of surrounding rock of roadway in improved scheme.

In addition, the transportation roadway is approximately $1,000 \mathrm{~m}$ underground, and the burial depth is large. In this area, the maximum horizontal principal stress value is $20 \mathrm{MPa}$, the side pressure coefficient is approximately 1.1 , and a high stress exists. Moreover, a large amount of strain energy is accumulated in the deep rock mass, which results in severe dynamic disasters. The floor is mainly composed of sandy mudstone and mudstone, which have low strength. In the process of tunneling, a large amount of water generated by drilling will reduce the strength of the rock under the floor, and the roadway passes through three faults and two coal lines, with a large drop. The lithology is poor, the structure is relatively developed, and the strength and stability of the surrounding rock are low. These result in significant expansion and creep deformation of the soft rock. Therefore, the floor heave is substantial and difficult to control.

\section{Control Measures}

5.1. Field Control Technology. According to the deformation mechanism of the surrounding rock, the following requirements are put forward. The range of the load-bearing ring and decreasing stress area of the floor of a deep high-stress roadway is larger than that of the roof, so the first step is to support the floor. Because the roof, two sides, and floor are mostly mudstone, or a similar material, the stability is poor, so the surrounding rock needs to be reinforced by grouting. The stress concentration in the key parts of the floor and roof 


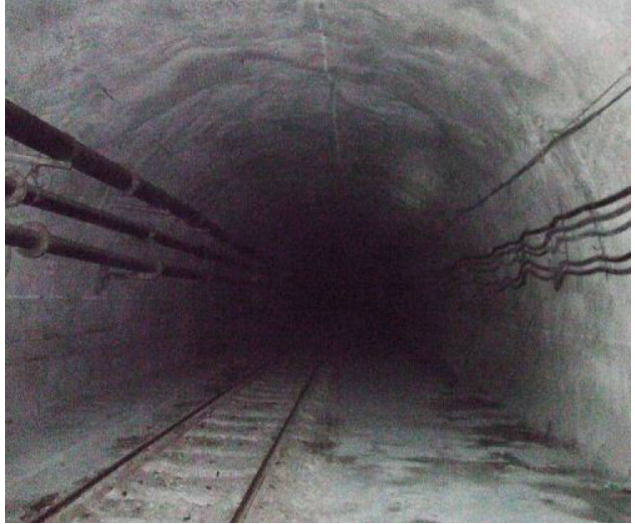

FIGURE 15: The supporting effect diagram.

corners can be damaged easily, so the supports need to be strengthened, which can block the transfer of stress from the sides to the floor.

The supports should consist of spatiotemporal coupling, so that the roof, floor, two sides, and the key parts can be effectively maintained within the service life of the roadway. Based on this requirement, overexcavation anchor injection backfilling technology can be used to comprehensively control the floor heave of the deep high-stress roadway [26, 27]. The specific measures are as follows: after the excavation of the tunnel, $50 \mathrm{~mm}$ of concrete is initially sprayed, and then the wire mesh is hung; then, the prestressed and highstrength anchor bolts are used for the shotcreting support of the anchor mesh, and the prestressed anchor cable support is placed in the key parts (top angle and bottom angle), and then a second $100 \mathrm{~mm}$ layer of shot concrete is sprayed. After the convergence of the tunnel in the initial deformation stage, the floor is grouted and reinforced. In areas with unfavorable engineering geological conditions, the roof and key parts are grouted, and the floor is backfilled with concrete via overexcavation. The specific support parameters and design drawings are shown in Figure 13.

5.2. On-Site Monitoring. After the completion of construction, a multipoint displacement meter should be installed in the surrounding rock, and 6 measuring points should be installed in the roof and sides at $1 \mathrm{~m}, 2 \mathrm{~m}, 3 \mathrm{~m}, 4 \mathrm{~m}, 5 \mathrm{~m}$, and $6 \mathrm{~m}$ from the roadway surface; 8 measuring points should be installed in the floor at $1 \mathrm{~m}, 2 \mathrm{~m}, 3 \mathrm{~m}, 4 \mathrm{~m}, 5 \mathrm{~m}$, $6 \mathrm{~m}, 8 \mathrm{~m}$, and $10 \mathrm{~m}$ from the roadway surface. The field observation results of the measurement points in the surrounding rock of the tunnel are shown in Figure 14.

The displacement and velocity of the roof and the two sides decreased significantly. After 60 days, the displacement after the installation of the new support was approximately $50 \%$ less than that with the original scheme, while the displacements of the two sides were $25 \%$ less than that with the original scheme. Moreover, 35 days after the excavation of the roadway, there was no significant change in the roof and the two sides of the roadway. Although the initial deformation of the floor was slightly larger than that before the improvement, the deformation rate of the floor was significantly reduced, and the duration of the floor displacement in the fissure development stage was significantly shorter than before, which went from 15 days to within 6 days. Therefore, it was verified that the new support scheme could effectively control the surrounding rock (Figure 15).

\section{Conclusions}

In order to prevent continuous high-speed deformation of roadway floors, simulation experiments were conducted to restore a horizontal transportation rock roadway at the Xieyi Mine. This study analyzes the displacement and deformation trends and stress changes of a soft rock roadway under high ground stress. On this basis, two requirements are proposed: (1) controlling the roof requires controlling the two sides, and controlling the two sides requires protecting the floor and (2) controlling the floor requires controlling the two sides first, and controlling the two sides requires controlling roof first. The conclusions are as follows:

(1) The similar simulation used a four-way loading plane frame to carry out the experiment. By loading different pressures on the roof, two sides, and floor to replicate the high-stress environment of the site, the roadway damage could be closer to the site to better analyze the failure mechanism of surrounding rock

(2) After the excavation of the experimental roadway, in the process of seeking the equilibrium of the roadway under pressure loading, the surrounding rock failure could be divided into three stages: the initial deformation stage (failure time $0-0.5 \mathrm{~h}$, failure range $0.4 \mathrm{~m}$ ), the fissure development stage (failure time $0.5-2 \mathrm{~h}$, failure range $1 \mathrm{~m}$ ), and the mild deformation stage (failure time $2-6 \mathrm{~h}$, failure range $1.5 \mathrm{~m}$ ).

(3) Stress first starts to concentrate in key parts, and the range expands with time. The floor is not supported, and the high stress is continuously transferred to the floor. The floor breaks first, then the surrounding rock balance breaks, causing damage to the sides, further causing the roof to sink and further damage to the floor until the roadway is destroyed. After the floor is destroyed, its damage range exceeds that of the roof

(4) By fitting the curves of the displacements of the roof, two sides, and floor of the surrounding rock using the experimental data, the authors found that roof subsidence, the displacement of the two sides, and floor heave have mutual influences on each other. The authors then proposed the idea of the trinity coupling support. That is, the floor is first supported, and then the two sides and the roof are supported to form the trinity coupling support method to control the deformation of the surrounding rock for the lifetime of the roadway and achieve space-time coupling

(5) Applying the concept of the trinity coupling support to the site, the deformation of the roof and two sides was effectively restricted, the deformation rate of the 
floor was significantly reduced, and the surrounding rock of the tunnel was effectively controlled

The similar simulation experiment used in this paper restored the high-stress environment in the deep part of the site. The selected similar materials were only determined from the primary components and could not be completely consistent with the site. The values of stress and displacement of the surrounding rock were slightly different, but the change mechanisms will remain consistent. Adopting the supporting concept of this paper can provide an effective control scheme for roadways under similar engineering geological conditions.

\section{Data Availability}

The data used to support the findings of this study are available from the corresponding author upon request.

\section{Conflicts of Interest}

The authors declare that there is no conflict of interest regarding the publication of this paper.

\section{Acknowledgments}

This work is supported by the National Natural Science Foundation of China (No. 51774009), Key Research and Development Program of Anhui Province (No. 202004a07020045), and Natural Science Foundation of Anhui Province (2008085QE226).

\section{References}

[1] R. G. Gurtunca, "Mining below 3000m and challenges for the South African gold mining industry," Mechanics of jointed and faulted rock, pp. 3-10, 1998.

[2] X. B. Li, D. A. Summers, G. Rupert, and P. Santi, "Experimental investigation on the breakage of hard rock by the PDC cutters with combined action modes," Tunnelling and Underground Space Technology, vol. 16, no. 2, pp. 107-114, 2001.

[3] D. H. Diering, "Ultra-deep level mining: future requirements," Journal of the Southern African Institute of Mining and Metallurgy, vol. 97, no. 6, pp. 249-255, 1997.

[4] M. Vogel and H. P. Rast, "AlpTransit-safety in construction as a challenge: health and safety aspects in very deep tunnel construction," Tunnelling and Underground Space Technology, vol. 15, no. 4, pp. 481-484, 2000.

[5] C. Li, Z. Wang, and T. Liu, "Principle and practice of coupling support of double yielding shell of soft rock roadway under high stress," International Journal of Mining Science and Technology, vol. 24, no. 4, pp. 513-518, 2014.

[6] H. P. Kang, J. Lin, and M. J. Fan, "Investigation on support pattern of a coal mine roadway within soft rocks - a case," International Journal of Coal Geology, vol. 140, pp. 31-40, 2015.

[7] Q. Chang, H. Zhou, Z. Xie, and S. Shen, "Anchoring mechanism and application of hydraulic expansion bolts used in soft rock roadway floor heave control," International Journal of Mining Science and Technology, vol. 23, no. 3, pp. 323-328, 2014.
[8] P. Gong, Z. Ma, X. Ni, and R. R. Zhang, "Floor Mechanism of Gob-Side Entry Retaining with Fully-Mechanized Backfilling Mining," Energies, vol. 10, no. 12, p. 2085, 2017.

[9] J. Sun and L. G. Wang, "Numerical simulation of grooving method for floor heave control in soft rock roadway," Mining Science and Technology, vol. 21, no. 1, pp. 49-56, 2011.

[10] M. Sungsoon, K. Tutuk, and S. Saydam, "Management of floor heave at Bulga Underground Operations-a case study," International Journal of Mining Science and Technology, vol. 29, no. 1, pp. 73-78, 2019.

[11] S. Mo, P. Sheffield, P. Corbett et al., "A numerical investigation into floor buckling mechanisms in underground coal mine roadways," Tunnelling and underground space technology, vol. 103, article 103497, 2020.

[12] W. Zheng, Y. Zhao, and Q. Bu, “The coupled control of floor heave based on a composite structure consisting of bolts and concrete antiarches," Mathematical Problems in Engineering, vol. 2018, 14 pages, 2018

[13] X. Lai, H. Xu, P. Shan, Y. Kang, Z. Wang, and X. Wu, "Research on and Control of Floor Heave of MiningInfluencedRoadway in Top Coal Caving Working Face," Energies, vol. 13, no. 2, p. 381, 2020.

[14] C. K. Liu and J. X. Ren, "Panel roadway floor heave mechanism and control technology," EJGE, vol. 21, no. 11, pp. 4039-4048, 2016.

[15] Y. Chen, J. Bai, S. Yan, Y. Xu, X. Wang, and S. Ma, "Control mechanism and technique of floor heave with reinforcing solid coal side and floor corner in gob-side coal entry retaining," International Journal of Mining Science and Technology, vol. 22, no. 6, pp. 841-845, 2012.

[16] C. Wang, Y. P. Wu, and X. P. Huang, "Failure mechanism and control of back arch support of roadway floor under complex surrounding rock conditions," Journal of Mining and Safety Engineering, vol. 36, no. 5, pp. 959-967, 2019.

[17] R. Cao, P. Cao, and H. Lin, "Support technology of deep roadway under high stress and its application," International Journal of Mining Science and Technology, vol. 26, no. 5, pp. 787-793, 2016.

[18] P. Cao, H. Y. Li, Y. F. Zhong, and F. Wang, "Mechanism analysis and control of deep-buried high side pressure roadway floor heave," Journal of Central South University (Natural Science Edition), vol. 48, no. 2, pp. 457-464, 2017.

[19] X. M. Sun, F. Chen, M. C. He, W. L. Gong, H. C. Xu, and H. Lu, "Physical modeling of floor heave for the deep-buried roadway excavated in ten degree inclined strata using infrared thermal imaging technology," Tunnelling and Underground Space Technology, vol. 63, pp. 228-243, 2017.

[20] X. Sun, D. Wang, J. Feng, C. Zhang, and Y. Chen, "Deformation control of asymmetric floor heave in a deep rock roadway: a case study," International Journal of Mining Science and Technology, vol. 24, no. 6, pp. 799-804, 2014.

[21] G. Guo, H. Kang, D. Qian, F. Gao, and Y. Wang, "Mechanism for controlling floor heave of mining roadways using reinforcing roof and sidewalls in underground coal mine," Sustainability, vol. 10, no. 5, p. 1413, 2018.

[22] J. Wang, Z. Guo, Y. Yan, J. Pang, and S. Zhao, "Floor heave in the west wing track haulage roadway of the Tingnan Coal Mine: mechanism and control," International Journal of Mining Science and Technology, vol. 22, no. 3, pp. 295-299, 2012.

[23] Z. Guo, J. Wang, and Y. Zhang, "Failure mechanism and supporting measures for large deformation of tertiary deep soft 
rock," International Journal of Mining Science and Technology, vol. 25, no. 1, pp. 121-126, 2015.

[24] P. Kulatilake, Q. Wu, Z. Yu, and F. Jiang, "Investigation of stability of a tunnel in a deep coal mine in China," International Journal of Mining Science and Technology, vol. 23, no. 4, pp. 579-589, 2013.

[25] Z. Mu, G. Liu, J. Yang et al., "Theoretical and numerical investigations of floor dynamic rupture: A case study in Zhaolou Coal Mine, China," Safety Science, vol. 114, pp. 1-11, 2019.

[26] G. X. Xie and J. C. Chang, "Research on the control of deep roadway floor heave by over-excavation anchor-grouting backfill," Journal of China Coal Society, vol. 35, no. 8, pp. 1242-1246, 2010.

[27] J. C. Chang and G. X. Xie, "Mechanical characteristics and stability control of surrounding rock in deep roadway," Journal of China Coal Society, vol. 34, no. 7, pp. 881-886, 2009. 